\title{
Turismo gastronômico, cultura e comida de festa
}

\author{
Food tourism, culture and feast food
}

\author{
Ana Maria Costa Beber \\ Universidade de Caxias do Sul, Brasil \\ galáxia_ana@hotmail.com \\ Susana Gastal \\ Universidade de Caxias do Sul, Brasil \\ susana.gastal@gmail.com
}

\begin{abstract}
Resumo
As migrações da Península Itálica para o sul do Brasil datam da segunda metade do século XIX. As adaptações ao novo território marcaram as práticas culinárias desses grupos. Este artigo apresenta a situação atual das comunidades originadas na imigração, em termos de suas práticas alimentares associadas às festas locais e, consequentemente, ao turismo. O procedimento metodológico retomou pesquisas anteriores no mesmo local, utilizando seus dados primários. Depois, realizaramse entrevistas semiestruturadas com mulheres, que atualmente vivem na mesma comunidade. Os resultados comparados mostram mudanças associadas à origem dos ingredientes, uso de novas tecnologias e introdução de produtos industriais, bem como uma nova organização nos menus. Pratos cotidianos tornaram-se parte da chamada comida de festa, depois apresentados aos turistas como marcas de identidade da comunidade local.
\end{abstract}

Palavras-chave: gastronomia; alimentação ítalo-brasileira; comida de festa; Antônio Prado-RS, Brasil.

\begin{abstract}
Migrations from the Italian peninsula to the south of Brazil date from second half of nineteenth century. Adaptations to the new territory marked culinary practices of these groups. This article presents current situation of communities which originated in immigration, in terms of their food practices associated with local feasts, and, consequently, with tourism. The methodological procedure took up previous research in the same location, using its primary data. Afterwards, we conducted semi-structured interviews with women who currently live in the same community. Compared results show changes associated with origin of ingredients, use of new technologies and introduction of industrial products, as well as a new organization in menus. Everyday dishes have become part of the so-called feast food and are presented to tourists as marks of local community identity.
\end{abstract}

Keywords: gastronomy; Italian-Brazilian food; feast food; Antonio Prado-RS, Brazil.

\section{Introdução}

A relação entre gastronomia e turismo (food tourism) apresenta, ainda poucas pesquisas acadêmicas, com estudos mais consistentes apenas a partir da década de 1990, no âmbito do que se marcará como Pós-modernidade. Nas décadas finais do século XX, constata-se a ampliação conceitual no entendimento da Cultura, passando a ser reconhecido, como produto cultural, entre outros, a gastronomia. Há, ainda, uma ênfase no passado, na nostalgia e no

Dos Algarves: A Multidisciplinary e-Journal, $30-2017$.

ISBN 2182-5580 @ ESGHT - University of the Algarve, Portugal.

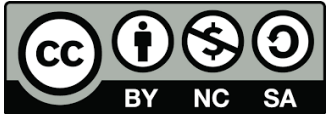

To cite this article: Beber, A. \& Gastal, S. (2017). Turismo gastronômico, cultura e comida de festa. Dos Algarves: A Multidisciplinary e-Journal, 30, 58-71. doi: 10.18089/DAMeJ.2017.30.5 
'autêntico', em muito associada às ruralidades e nelas, com destaque, a comida. Sims (2009: 321) apresenta o "produto 'autêntico' como aquele que simboliza o lugar e a cultura da destinação" (ver também Du Rand \& Heath, 2006; Du Rand, Heath \& Alberts, 2003; Everett, 2008; Gastal, 2006).

Everett (2008: 339), por sua vez, defende que os estudos acadêmicos devem originar conhecimento turístico que destaque as diversidades, "demarcando um caminho para os estudos turísticos evoluírem para uma ciência social mais crítica e aberta para interpretação cultural". Ainda segundo a autora, a comida pode indicar significados que enfatizarão o viés teórico da pluralidade, na experiência turística. Bertella (2011) destaca diferentes conhecimentos gerados nas pesquisas com foco na gastronomia, entre eles, a contribuição ao conhecimento em Turismo, ao conhecimento em gestão e marketing, e à reflexão sobre as relações local-global, entre outros. Destaca, ainda, que políticas em relação ao turismo gastronômico devem estar baseadas "nas peculiaridades e especificidades do terroir. Para tal são necessárias investigações que busquem tais especificidades, que posteriormente venham a alimentar redes e bases de conhecimentos" (Bertella, 2011: 355).

O presente estudo trata da alimentação ítalo-brasileira considerando-a como expressão cultural, e como tal inserida nas propostas de turismo cultural no município de Antônio Prado, no Estado do Rio Grande do Sul. O turismo cultural é interpretado como uma atividade que visa estabelecer contato e vivência entre o turista e a população local através de experiências de compartilhamento de modos de vida, hábitos cotidianos e anticotidianos, manifestações artísticas, arquitetura, festas, alimentação, entre outras. Entende-se que para pensar a experiência é importante considerar o background cultural de turistas e da comunidade local. Neste sentido, a alimentação ítalo-brasileira não é tratada aqui no âmbito do turismo gastronômico, mas sim como um produto de consumo, cujo contexto se estabelece na condição de modos de vida cotidianos de alimentação de (i)migrantes itálicos e seus desdobramentos como comida cotidiana, comida de festa e oferta turística. Essas ideias permitem pensar os importantes processos culturais que envolvem os estabelecimentos dos migrantes no sul do Brasil, na segunda metade do século XIX, oriundos da península itálica, e que ainda na atualidade alimentam as identificações ${ }^{1}$ locais.

A comida é uma das formas de refletir sobre tais processos, para tal considerando-se: (a) as receitas herdadas; os ingredientes utilizados, em especial se originados de espécies e variedades nativas; (b) as práticas cotidianas e as festivas, presentes nas comemorações comunitárias, familiares e turísticas, quando as práticas culinárias estão entre os principais atrativos nos eventos promovidos em torno da italianidade; (c) os rituais associados ao preparo e ao consumo dos pratos; e, não menos importante, (d) os imaginários associados, que levam à valorização de pratos vistos como tradicionais e, nessa condição, arrolados como patrimônio imaterial pelas autoridades patrimonialistas. Os imaginários alimentam e são alimentados por discursos, levando a que a comida se inclua como item de identificação do grupo.

Para tanto, como procedimentos metodológicos foram retomados os depoimentos contidos nos projetos "Salvamento do Patrimônio Histórico e Cultural nas Áreas do Complexo Energético Rio das Antas" cujas falas dos depoentes, idosos na sua maioria, reportam às primeiras décadas do século XX, utilizando-as como documentos e dados primários; e o

\footnotetext{
${ }^{1}$ Seguindo Hall (2003), utiliza-se identificação e não identidade, pois na atualidade, as referências a alimentar a autoconstrução dos sujeitos seriam mais complexas, em processos que tornam o território (antes sustentáculo das identidades), uma referência entre muitas outras.
} 
“Inventário da Diversidade Cultural da Imigração Italiana: o Talian e a Culinária”, ${ }^{2}$ estudo que trata da cozinha rural, por sua interligação direta com os recursos locais, sendo assim uma cozinha rigorosamente territorial. De outro lado, o tipo de transmissão da cultura, inclusive a gastronômica, no âmbito de tal ruralidade, se faz pela transmissão familiar, no meio doméstico, e pelo aprendizado na(s) rede(s) de vizinhança, com pouca influência externa, e que tende a se incorporar também na tradição local preexistente (Piazza \& Pozenato, 2005). Destaca-se a importância metodológica dos dois projetos, que inventariaram a memória, apoiados na História Oral. Os dados neles contidos permitem reconstituir o contexto em que se compõe essa cozinha rural 'da colônia', que se quer 'italiana' nos imaginários locais, e sua rede de relações com a tradição e o território.

Prosseguindo com a História Oral como base metodológica, a atualização da pesquisa realizou novas entrevistas, com roteiro semiestruturado, com sete senhoras que, no ano de 2015, viviam em Antônio Prado (2015), buscando atualizar com depoimentos contemporâneos, os dados das pesquisas anteriores. Os nomes das entrevistadas são fictícios, para preservar a sua identidade. Foram ouvidas as senhoras Júlia, 76 anos; Lina, 69 anos; Rosa, 61 anos; Gema, 60 anos; Beatriz e Inês, 57 anos; e Vera, 53 anos. Para a análise, os dados foram elencados em indicadores que emergiram do corpus de pesquisa, sendo selecionados três para o presente artigo, quais sejam: almoço festivo, almoço de dia de festa e almoço de domingo. O texto a seguir inicia por destacar a formação culinária da cidade de Antônio Prado para, a seguir, abordar as refeições coletivas que são o almoço festivo, o almoço de domingo e o almoço de dia de festa, com respectivas reflexões das autoras.

\section{Turismo e gastronomia}

Everett (2008: 338, 346) caracteriza como turismo gastronômico, "a visitação a produtores agrícolas primários e secundários, a festivais gastronômicos, restaurantes e locais específicos [...] com o desejo de experienciar um tipo particular de comida ou a produção de uma região específica". Tais visitas seriam instigadas por imaginários "conectados como algo perdido no passado", levando a busca por lugares onde estariam expostos "a certos cheiros, sabores e o toque de certos alimentos".

Outros autores indicam o turismo gastronômico como um nicho de mercado, também associado ao segmento de turismo alternativo, baseado na agricultura, na cultura e na infraestrutura turística, como aquele em que os turistas desejariam, antes do que novos lugares, novas experiências. Nesses termos, a comida deixaria de envolver apenas resorts, hotéis e restaurantes, para significar a experiência no e com o local (Du Rand \& Heath, 2006; Sims, 2009). O turismo gastronômico acrescentaria ao local: reconhecimento cultural; promoção turística; incentivo à produção agrícola; competitividade; um indicativo da relação global-local; atração de um turista com padrões de consumo e preferências específicas, levando ao respeito aos ecossistemas do lugar (Nummedal \& Hall, 2006; Du Rand et al., 2003).

Para Du Rand e Heath (2006: 6), em termos práticos, "a identidade nacional é refletida e reforçada pela experiência gastronômica que oferta”. Nummedal e Hall (2006), investigando as práticas do setor e a percepção local sobre a produção de alimentos na Nova Zelândia, entre

\footnotetext{
${ }^{2}$ A pesquisa é objeto do Convênio de n. $^{\circ} 701773 / 2008$, celebrado entre o Instituto do Patrimônio Histórico e Artístico Nacional (IPHAN) e o Instituto Vêneto - Associação Cultural-Educacional Novo Vêneto, que teve como partícipes a Universidade de Caxias do Sul (UCS) e a Federação das Associações Ítalo-Brasileiras do Rio Grande do Sul (FIBRA-RS).
} 
outros, destacam a necessidade de 'educar' (aspas dos autores) os membros da cadeia local de comida, sobre os benefícios da relação com o turismo, destacando o consumidor como um elo importante nesta cadeia. Isso seria alcançado, primeiramente, por pesquisas que levem ao maior conhecimento sobre a diversidade e a cultura alimentícia local. Só assim, sob o ponto de vista do mercado, a gastronomia reforçaria a imagem do lugar, sua competitividade e sustentabilidade, beneficiando produtores tanto da agricultura familiar como da indústria alimentícia, ao agregar valor de marca aos seus produtos (Du Rand \& Heath, 2006).

Considera-se também a forte ligação entre o alimento e os valores, as crenças e o estilo de vida dos sujeitos envolvidos no seu preparo e consumo, ou seja, a comida materializando modos pessoais e coletivos de ser, fazer, viver e estabelecer relações, que vão além do alimentar-se (DaMatta, 1986). Compreende-se a partir de Alfonso (2005), que a forma como o alimento é produzido, elaborado e consumido traduz a maneira como os indivíduos de diferentes sociedades projetam as suas identidades. Tem-se, que a comida está vinculada à cultura do lugar, aos alimentos ali produzidos e ao modo como são combinados ao serem preparados. Ao tratar do trabalho cotidiano nas cozinhas, Certeau, Giard e Mayol (2011) defende que este é uma forma de unir matéria e memória, vida e ternura, o presente e o passado, a invenção e a necessidade, a imaginação e a tradição, tudo imerso nos gostos, cheiros, cores, sabores, formas, consistências, atos, gestos, movimentos, coisas e pessoas, calores, sabores, especiarias e condimentos.

Este conjunto de elementos que compõem o ato alimentar impregna as representações simbólicas que conformam identidades e, em muitos casos, patrimônios locais. Por outro lado, modos de produção, saberes, fazeres, rituais de comensalidade e festas, entre outros associados ao alimento, são atualmente percebidos e incorporados pela sociedade como produtos de consumo turístico. Para Schlüter (2003), a gastronomia está entre as novas demandas dos turistas, por se tratar de uma manifestação em evidência em outras esferas sociais e culturais. Segundo Gastal (2003), a contemporaneidade trouxe a revalorização das minorias étnicas e das ruralidades, levando à reconstrução das tradições locais, a partir de imaginários associados à autenticidade e pureza. Promove-se, assim, crescente oferta de comidas étnicas ou regionais tradicionais no contexto do turismo, tanto para consumo local como na sua incorporação a guisa de souvenir gastronômico, presentes nos itens de compras dos turistas. $O$ alimento e a alimentação, para além de sua tradicional presença entre os itens necessários à infraestrutura da oferta turística, passam a ser destacados também como atrativos.

\section{Formação culinária de Antônio Prado}

Os primeiros migrantes chegaram ao local onde hoje está a cidade de Antônio Prado em 1886, procedentes já por migração interna, vindos de outras colônias do sul do Brasil. Tratavam-se de camponeses vindos de territórios que hoje formam a Itália, como os vicentinos, beluneses, mantuanos, cremoneses, trentinos, entre outros. Na atualidade, o município de Antônio Prado apresenta 13,285 habitantes, com uma taxa de analfabetismo de 4,81\% e expectativa de vida de 75,07 anos, com um IDH de 0,758, e um PIB per capita de 7,724 euros. ${ }^{3}$ Importante destacar que a localidade integra uma região com forte apelo turístico, no extremo sul do Brasil. Destaca-se dos demais na região, por um acervo arquitetônico composto de quarenta e oito edificações em madeira, tombadas pelo Instituto do Patrimônio Histórico e Artístico

\footnotetext{
3 Conforme câmbio em 08 outubro 2016.
} 
Nacional (IPHAN), e pela qualidade associada à gastronomia ali praticada, que ganha visibilidade através de duas festas anuais, de apelo turístico: a Noite Italiana e a Festa Nacional da Massa (Fenamassa).

Os primeiros grupos de migrantes a se estabelecerem em Antônio Prado defrontaram-se com áreas ainda de mata virgem, sendo necessária a derrubada de árvores para abertura de clareiras e, só então, se dando o cultivo. Com isso, houve uma adaptação das técnicas, dos procedimentos de cultivo, dos hábitos alimentares e de toda cultura culinária. Herédia e Tronca (2016: 346), referindo outra localidade da região, mas de mesmo perfil geográfico, explicam que o "local era semelhante ao deixado na terra de origem, marcado pela presença de morros e por terrenos com pedras, onde os recém-chegados realizavam uma agricultura de subsistência, já que a situação geográfica não era propícia à agricultura extensiva ou à criação de gado".

Tais situações adversas, entretanto, não seriam muito piores que aquelas das terras de origem, pois, segundo as mesmas autoras, a "crise econômica que marcou o final do século XIX foi um cenário que a maioria dos imigrantes italianos não esqueceu, sendo a fuga da miséria o principal motivo do abandono à pátria. De regiões bastante distintas, muitos foram obrigados a emigrar para sobreviver" (Herédia \& Tronca, 2016: 346). Depois de estabelecidos, há o isolamento na Colônia - denominação dada às terras concedidas pelo Governo aos imigrantes -, pela falta de estradas, pela carência de recursos financeiros, pela inexistência de comércio local onde pudessem adquirir produtos e colocar para comercialização a produção da propriedade rural. Este cenário leva a mudanças importantes nos modos de vida cotidianos das famílias imigradas, sendo a alimentação apenas um dos campos afetados (Lorenzoni, 1975).

Montanari (2013) relata que, historicamente, quando há carestia e redução da variedade de produtos alimentícios, são desencadeadas estratégias de sobrevivência que têm como regra comum a busca pela permanência, o máximo possível, das práticas alimentares cotidianas, ou seja, o mais próximo da cultura original dos grupos sociais. O que se mostraria similar nos casos de penúria seria que, na maneira de adaptar a produção agrícola tendo em vista a substituição de ingredientes e receitas, haveria a permanência de referências às práticas alimentares tradicionais. É nesta direção que o presente artigo busca refletir sobre as mudanças na comida ítalo-brasileira que se organiza nesse cenário sócio-histórico, de produto de consumo à expressão de patrimônio cultural ligado ao turismo, em Antônio Prado.

As origens europeias dos migrantes reforçam o imaginário de italianidade, com discursos que reiteram as práticas culinárias locais como 'cozinha italiana' (Piazza \& Pozenato, 2005), hoje utilizada como apelo turístico, em especial nos dois eventos já citados. Isso leva a que se autointitule, por decreto municipal, como a "Cidade mais italiana do Brasil", baseada na representatividade de seu patrimônio material e imaterial, este incluindo além da gastronomia, o dialeto vêneto ainda praticado, o artesanato, a religiosidade e os modos de vida de seu cotidiano, que mobilizariam as identificações da comunidade local com a italianidade, embora tais processos culturais hoje se deem em contexto multicultural, devido a migrações internas.

Para Piazza e Pozenato (2010), um dos fatores determinantes na formação da culinária local foi o seu isolamento nas décadas iniciais, devido à ausência de acessos que conectassem a cidade com outras regiões do Estado e do país. Como resultado desse isolamento geográfico no período, os ingredientes utilizados nas cozinhas eram produzidos na propriedade rural, sem 
acréscimos externos. Ainda segundo os mesmos autores, o processo histórico de formação da cozinha de imigração italiana de Antônio Prado passa por três fases e expressa a diversidade cultural deste fenômeno. São elas: fase da construção, fase da consolidação ou afirmação e fase de expansão ou reconstrução.

A fase de construção apresenta como aspectos principais: (a) as trocas de saberes culinários entre os familiares de imigrantes, que provinham de diferentes tradições alimentares no norte da Itália; (b) a ampliação das famílias através dos casamentos da segunda geração; (c) a identificação, teste e incorporação de produtos e ingredientes locais, tais como a da farinha de mandioca ${ }^{4}$, do melado de cana, de ervas, de frutas silvestres, do amendoim no lugar da amêndoa, e do pinhão; (d) e a aceitação de hábitos alimentares da tradição local, como o Churrasco ${ }^{5}$ e o Chimarrão. ${ }^{6}$ Esta fase dura por três gerações, iniciando por aqueles que emigraram, tendo como sequência as duas primeiras nascidas no Brasil, e finalizando na década de 1930. Ainda, as mudanças ocorridas se dão em âmbito doméstico, incluso nas refeições de domingo e festivas (Piazza \& Pozenato, 2010).

A segunda fase, denominada de consolidação ou afirmação, perdura por três ou quatro décadas, finalizando quando da inauguração da ponte do Passo Zeferino, em 1968. Esse período marca-se pela transição de uma cozinha doméstica para espaços coletivos, em que a 'festa do santo' nas paróquias católicas torna-se destaque, pois reúne a comunidade, recebe os 'de fora' e reagrupa famílias residentes em locais distantes. Com isso, há divulgação da comida pelos 'de fora' e se consolidam os modos de fazer na própria comunidade e com as famílias distantes. Há definição da sintaxe ${ }^{8}$ do almoço festivo da região, composto pela Sopa de Agnolini ou Capeleti, a Carne Less $a^{9}$ com saladas, a massa e as carnes, com poucas variações. Há, ainda, o consenso quanto a padrões de qualidade, tanto na escolha dos ingredientes como nos modos de fazer. A partir disto, alguns locais passam a ser identificados como lugares de referência por bem servir (Piazza \& Pozenato, 2010).

Para os autores, a terceira fase é nominada de expansão e tem duplo movimento. $O$ primeiro deles é o ingresso da cozinha rural nos restaurantes urbanos, que se dá de duas formas: (a) o cânone festivo rural do almoço doméstico; (b) a festa do santo é transferida para os restaurantes, com incorporação de pratos de outras procedências, tais como a Polenta Brustolada ${ }^{10}$ e o Churrasco. O segundo movimento é a incorporação de trocas, inclusive no âmbito internacional, ou seja, há inserção de padrão de gosto entendido como sofisticado, que incorpora e até substitui ingredientes na cozinha tradicional, como o azeite de oliva no lugar da banha ou óleos vegetais, aceto balsâmico no lugar do vinagre de vinho, entre outros.

\footnotetext{
${ }^{4}$ Aipim:planta arbustiva da família das Euforbiáceas, nativa da Américado Sul, cuja raiz tuberosa é rica e $m$ hidratos de carbono, fibras e vitaminas, cuja raiz é largamente usada na alimentação, na forma original e em farinha (cf. https://www.infopedia.pt/dicionarios/lingua-portuguesa/mandioca, acesso em 06 outubro 2016).

5 Prato tradicional do sul do Brasil, em que a carne de gado é colocada em um espeto e assada diretamente junto ao fogo feito com madeira ou carvão.

${ }^{6}$ Infusão de erva mate, servida em porongo e sorvida através de uma bomba.

7 Quando as comunidades já se organizaram em "capelas" - que têm a dupla função de ser centro religioso e centro de vida social - a rede de relações expande-se e passa a existir entre as comunidades, tendo a "festa do santo" como evento maior de socialização e também de negociação entre fronteiras (Piazza \& Pozenato, 2010).

${ }^{8}$ Segundo Montanari (2013), a sintaxe corresponde à refeição, ao ordenamento dos pratos de acordo com critérios de sequência, de associação e de relação recíproca.

${ }_{9}^{9}$ Alimento preparado com carnes cozidas na água fervente, coadas e depois temperadas a gosto. $O$ caldo era utilizado no preparo de sopas, especialmente a de Agnolini.

${ }^{10}$ Feita a partir de farinha de milho.
} 
No entendimento de Piazza e Pozenato (2010), a cozinha colonial de Antônio Prado é uma cozinha de pobreza (não cabe, porém, falar-se em miséria e em fome, que existiram, sim, nos primeiros anos da imigração e permaneceram como ameaça permanente sobre as cabeças das mães de família). Segundo os autores, a comida cotidiana seria simplória, as refeições incluíam um prato único, por vezes acompanhado por legumes ou carnes, devido à escassez de recursos, limitados a disponibilidades na propriedade, e ao ciclo sazonal. Com isso, os produtos abundantes tornam-se a base da alimentação cotidiana, com destaque na Polenta à base de farinha de milho, prato de sustento diário. Como consequência da 'pobreza' percebem-se invenções interessantes, como os pulmões do porco em quitute ou flores de abóbora fritas.

Ainda segundo Piazza e Pozenato (2010), o agricultor fazia quatro refeições ao dia, a primeira delas uma refeição rápida, antes de ir para o local de cultivo, em geral com café, pão e alguma marmelada. A segunda, nominada colassión, era servida no meio da manhã, no local de cultivo, e incluía comida de sal e, algumas vezes, um copo de vinho; o almoço, chamado de pranzo, era considerado a refeição mais farta do dia, tendo normalmente a Polenta como prato principal, com algum acompanhamento. Algumas famílias serviam uma merenda do meio da tarde, chamada de merendin, própria das longas jornadas de trabalho no verão. O jantar, la sena, tinha como prato tradicional a sopa ou ministra, Polenta Brustolada e sobras do almoço, sendo servida no início da noite.

Destaca-se a ausência de carnes e a presença de derivados, tais como o salame e outros embutidos de carne de porco, e o queijo, todos de produção doméstica. Estas refeições correspondem ao universo rural do século $X X$ e, com o passar das décadas, houve modificações em função das mudanças na própria atividade produtiva rural, pelo acesso a luz elétrica, pela disponibilização de novos ingredientes, pela industrialização na alimentação, pela influência da mídia, entre outros fatores. Neste sentido, há consonância com Montanari (2008), quando aponta que o mecanismo de substituição incorpora estavelmente as variantes do sistema local, sobretudo na presença de produtos novos.

\section{Almoço festivo, almoço de domingo e almoço do dia da festa}

A reflexão em torno das refeições coletivas, que marcam momentos importantes na trajetória das famílias ítalo-brasileiras, se apoia em Woortmann (2006), quando se refere à refeição como um ato social e não privado, ritualizado, havendo diferenças entre o comer cotidiano (casa) e o comer cerimonialmente (em público). A necessidade de reproduzir relações sociais se materializa no caráter ritual e simbólico de convidar pessoas para comer. Sob essa perspectiva, o que está em jogo é o princípio da reciprocidade e da comensalidade. Deste modo, o 'almoço festivo', o 'almoço de domingo' e o 'almoço de dia de festa' permitem analisar as mudanças ocorridas nos modos de vida a partir das práticas alimentares ítalo-brasileiras.

Segundo Piazza e Pozenato (2010), o 'almoço festivo' se insere no âmbito doméstico e refere-se, principalmente, às festas de casamento e, com menor ênfase, ao Natal, Páscoa e aniversários. Para o casamento, evento principal, compravam-se roupas novas, especiarias e ingredientes destinados à preparação dos pratos. A mesa de festa apresentava abundância e variedade, além de vinho, servido com generosidade. Quanto aos convidados, destacam-se os familiares dos nubentes e os vizinhos, estabelecendo relações de vínculo com aqueles que viviam mais próximos e a quem se poderia recorrer por qualquer razão. No Natal e na Páscoa eram preparados almoços festivos, mas limitados à família, sem ampliação do círculo de convivência. Destacamos os relatos de Lina, Júlia e Gema sobre seus casamentos: 
No dia que eu casei, o pai fez uma recepção em casa, era bolinho de carne, bife empanado, bucho e caldo de galinha. Às nove horas foi servido. A sopa de pão, como era com caldo de galinha, caldo e pão, e depois o pai colocava bucho por cima, carne e salada. Casamos às duas horas da tarde, chegamos lá na casa do noivo, era seis da tarde, já era noite escura. Almoço não tinha, só café da manhã (Lina, 2015).

No meu casamento, me lembro de que era uma torta, mas era torta mesmo, feita em casa. Que delícia! A minha mãe fazia torta no final do ano, a gente se reunia com os tios, era a única festa que tinha do ano, não tinha aniversário, não tinha nada. Como a gente morava no sítio tinha mais espaço, os da cidade, ia todo mundo para lá. Minha mãe fazia torta. Fazia bolo. O recheio era goiabada (Júlia, 2015).

A nossa lá, goiabada, ela [mãe] pegava o suco da uva, fazia um creme, em vez de ser uvada. Tipo um 'sugo'. Gente, eu me lembro! Eu sinto até hoje, fico com água na boca... Que delícia. Com coco, minha mãe fazia com coco, ameixa preta e uma marmelada, pro nosso casamento (Gema, 2015).

Percebem-se as similaridades das falas das depoentes e do constatado por Piazza e Pozenato (2010) no que se refere à produção das comidas pelas mães e parentes para o dia do casamento, bem como a diferenciação entre a comida de festa e a comida cotidiana. Ainda, o relato elucida a capacidade da comida de remeter a lembranças familiares. Sob este aspecto, os relatos sobre a torta de casamento apresentam o que apontam Amon e Menasche (2008), de que a comida é uma voz que comunica, que manifesta emoções, sistemas de pertinências, significados de uma identidade coletiva que constrói a narrativa da memória social de uma comunidade.

O Natal, segundo as depoentes, era uma festa religiosa, a celebração do nascimento de Jesus, através da participação na Missa do Galo. A confraternização familiar se dava no almoço e a comida era a mesma que a servida nos domingos.

Esta ceia que tem hoje, não. Mas a gente comemorava com pinheiro, presépio e se tivesse sopa de Agnoline, frango ou Tortei, era boa, comida especial. No Natal era Agnoline ou Tortei ou frango, que era a mesma comida especial de domingo (Beatriz, 2015).

O 'almoço de domingo' difere da comida cotidiana e é compreendido como o dia do 'comer bem'. Ele consolida o cardápio, a sintaxe padrão da cozinha da imigração italiana. De modo geral inicia com a sopa, precedido da Carne Lessa (cozida para a preparação do caldo, ou brodo), das saladas ou conservas em vinagre, um prato de carne acompanhado de massa, ou o Risoto, e por fim, os doces de sobremesa. O vinho acompanhava o ritual de almoço. Ainda para Piazza e Pozenato (2010), o almoço do domingo é um evento matriarcal.

Domingo tinha uma coisa melhor, a sopa com uma carne. A mãe assava um frango no forninho. Polenta, pão, saladas. Nós tínhamos a horta, a nossa cenoura, rabanete, beterraba, raditi, brócolis, repolho, couve. Nós tínhamos tudo na horta, a mãe tinha tudo, pimentão, moranga. Saladas, nunca compramos. Época de moranga usava moranga, de abobrinha usava abobrinha. Nós íamos usando o que tinha na época. Fruta nunca faltava, tinha ameixa, maçãa, goiaba essas, aquela com a casca verde, do mato, não sei como se diria, pitanga. Frutas e saladas à vontade, tudo da época. A gente comprava açúcar, café, casquinha do cacau, para 
fazer. Café era para quando vinha visita ${ }^{11}$, mais no domingo, se visitava muito, no domingo as mulheradas se reuniam sempre (Beatriz, 2015).

Se fazia também os Capeleti, naquela época, era massinha fina. Quando se fazia esta massa com Pien ${ }^{12}$, a massa tinha algum molho. O dia que se fazia Pien, era sopa de brodo e o Pien metade, e a gente cortava em rodela, ficava que nem salame, se colocava junto. Sempre tinha pão (Vera, 2016).

Domingo, também, até carne de panela, tu podias cozinhar de noite, de dia estava bom, qualquer carne era dura, porque não tinha carne mole, que nem agora. Agora tu pega uma carne de pescoço, vai fazer uma sopa tu desmancha ela, antes de terminar [para] fazer o caldo. E uma vez era os 'bois de canga', como se diz. Seriam as carnes que não davam para fazer os bifes. Muitas vezes Tortéi era comida de domingo. Uma bela macarronada era comida de domingo (Rosa, 2016).

A comida relatada tinha relação direta com os ingredientes produzidos pela família ou no âmbito local. Era elaborada pelas mulheres e mantinha uma relação estreita com a comida de procedência. Mesmo com troca de ingredientes, se buscava o sabor da casa, da Itália. Para Amon e Menasche (2013), a nostalgia dos sabores passados serve de inspiração para buscar e recriar práticas alimentares atuais ou, ainda, "o mundo das comidas nos leva para casa, para nossos parentes e amigos, para os nossos companheiros de teto e de mesa. Essas pessoas que compartilham intensamente de nossa vida e intimidade" (DaMatta, 1986: 53).

Em relação à referência ao lugar da mãe como protagonista do ato de alimentar, de dar coesão à família, cada mulher cria seu próprio estilo, imprimindo seu toque especial, inventando uma maneira pessoal de caminhar através do recebido, do adaptado e do já feito, apropriando-se, desse modo, do saber. São os modos singulares de agir dependentes da ordem cultural, que diferem uma sociedade da outra. As hierarquias internas e os modos de proceder de uma geração a outra transformam as regras de ação e os modelos de comportamento (Certeau et al., 2011). Quanto às questões de aprendizado, Giard (2011) afirma que o interesse pela culinária exige uma memória múltipla: memória de aprendizado, memória de gestos vistos, das consistências. Para o autor, as práticas alimentares são objeto de aprendizado precoce, estando ligadas à primeira infância, ao mundo maternal; desta forma: "Comemos o que nossa mãe nos ensinou a comer - ou o que a mãe da nossa mãe nos ensinou a comer" (Giard, 2011: 219).

A mãe - era o sistema da nona -, sempre ela fazia, quando fazia Agnoline, eu sempre ali perto ajudando a moer [...]. Quando fazia Tortei, também ajudando a fechar. A gente vê, quer aprender, não precisa ficar dizendo, faz isto, faz aquilo (Júlia, 2016).

\footnotetext{
11 "Para esperar as visitas, a mãe fazia biscoito, Grostoli, biscoito de ovo, açúcar, um pouquinho de gordura, banha ou a gordura que a gente tinha era banha, leite, e não era muita coisa, a gente tinha a máquina de moer carne e tinha uma chapinha e saia o biscoitinho e a gente colocava nas latas, cozinhava no forninho a lenha, a gente não recheava nada, se fazia um bolo também nunca tinha cobertura" (Beatriz, 2016).

12 Pien: embutido feito com a pele do pescoço da galinha, recheado com guisado de frango desfiado, (temperado com pimenta, sal, cebola, alho e tempero verde, em geral sal e folha de cebola) adicionado ao pão amassado (farinha de rosca), noz-moscada. Cozinha num caldo de galinha e serve fatiado.
} 
Atualmente, a comida de domingo incorporou o Churrasco e a salada de batatas com maionese, descrita por Vera como segue:

A comida de domingo é Churrasco de carne de gado, saladinha de batata, quando eu tenho, maionese feita com salsinha, ovo picado, cebolinha, sal e azeite de oliva; alface, mandioca a gente come no lugar do pão, carne de gado, carne de ovelha, um porquinho, coração de boi também, moela e coração de frango. Uso tudo da horta, o que tem em cada época e nos dias frios a gente faz Agnoline, em casa, fininho (Vera, 2016).

A fala de Vera corrobora com a de Piazza e Pozenato (2010) ao apontar a incorporação do Galeto (ver Peccini \& Campillo, 2012) como criação urbana e do Churrasco como tradição regional 'Gaúcha' (do Estado do Rio Grande do Sul, no extremo sul do Brasil), mas ainda assim verifica-se que há continuidade dos pratos tradicionais. A entrada destes pratos pode ser interpretada como um símbolo da Modernidade, permitindo o pertencimento com uma identidade - identificação associada a uma nova época, a da luz elétrica e da cidade.

Em relação às sobremesas, nota-se que pertenciam às refeições de maior importância, as de domingo, de casamento e de Natal e, de modo geral, receitas simples, com o uso de ingredientes locais, produzidos no âmbito familiar, utilizando o leite, ovos, as frutas, o vinho e o suco de uva, entre outros.

Minha mãe gostava que a gente fizesse pudim de leite, e ainda faço. Ela me fazia descascar o figo, ainda faço, fazer figo em calda e a moranga em calda, [que] ela fazia com as casquinhas duras. Nossa! Nos domingos minha mãe queria fazer, ela gostava que tivesse uma sobremesa, ela fazia creme de laranja, tudo em xícara pequena e depois se virava dentro do potinho e se colocava um cravinho em cima (Vera, 2015).

Para Piazza e Pozenato (2010) o 'almoço do dia da festa' é representado pela 'sagra', que é a festa do santo padroeiro da comunidade e se constitui em um dos símbolos da cultura da italianidade trazida pelos imigrantes. Como evento religioso, inicia com a missa, procissão e, em alguns casos, a novena, seguindo-se de jogos variados, bem como banda de música (a mesma que acompanha, inclusive, a procissão) e os foguetes ou morteiros. Para elucidar, Gema e Lina relatam suas lembranças da 'sagra':

Lembro da gasosa, era gasosa que chamavam, era laranjinha. A Grapete... Eu sou do tempo de Grapete. Eu ainda peguei o meu pai fazendo Spritzel em casa. A mãe fazia com abacaxi o refrigerante (Gema, 2016).

la na missa rezar, depois a gente nem pegava o almoço, só a carne, ia para casa, porque a turma era muito grande. De tarde a gente voltava (Lina, 2016).

Ainda segundo os autores, o destaque da 'sagra' está no almoço festivo, tradição trazida da Itália, quando se reúnem parentes, membros distantes das famílias e citadinos, este evento ativava o círculo virtuoso de trocas e era um momento de articulação matrimonial, namoros e casamentos iniciavam nestas festas, tanto entre a própria comunidade como com os convidados de outros lugares: 
Ah, nestas festas, íamos na procissão, na missa, cantávamos, ganhava ou a mãe costurava roupa nova. Era uma festa. Tinha os parentes e os amigos de escola, era brincar, depois namorar também (Júlia, 2016).

O cardápio e a execução do almoço de festa ficavam sob a responsabilidade das cozinheiras mais competentes da comunidade e era organizado do seguinte modo: inicia com uma sopa de Agnolini ou Capelèti, acompanhada de queijo parmesão ralado e pão de trigo, seguida de Lessa e Pien, acompanhado do Cren (raiz forte ralada e curtida em vinagre de vinho tinto), de saladas e de outras conservas de vegetais em vinagre. Os pratos quentes eram a massa ou Risoto, carne de galinha e de leitão. Inês relata, como segue, a Festa da Gruta em Antônio Prado:

Na 'festa da colônia', na Festa da Gruta, a gente coloca ovo de colônia, mas não sei até quando. Como eu faço parte da comissão, a gente vai fazer Tortei na sexta-feira. A gente faz massa mesmo, aí a gente pega ovo de colônia, daí a fiscal [do Controle Sanitário de alimentos] não aparece lá, mas elas fiscalizam... Agora, dia 12 de outubro, a gente vai fazer a Festa de Aparecida lá, mas eu tive que pedir licença para ela para fazer os Agnolini, mas ela deixou fazer... Eles [Vigilância Sanitária] vêm, olham o local, dão umas explicações, os cuidados, enfim, o que não pode usar... Todos os anos na festa, uns dias antes, eles vêm e falam, para não dar problema e tal, se não se faz o Agolini ali, se faz o pescoço ali. A gente contrata uma cozinheira no caso, porque é muita gente, é quatrocentas, quinhentas pessoas, é para unir o pessoal. Disseram "não vai dar lucro esta festa", mas não é visar lucro, é para visar o convívio do bairro, porque nem sempre eles vão na festa, mas para fazer o Agnoline eles vão, o pessoal se reúne, depois vai ter o café com o Grostoli (Inês, 2015).

Para DaMatta (1986), a mesa reúne liberdade, respeito e satisfação, sendo um instante que permite invalidar as diferenças e oposições. Para o autor, é na mesa, através da comida cotidiana, que as pessoas comungam umas com as outras, num ato afetivo e sagrado, havendo a ênfase nas relações grupais e não individualizadas. No excerto de Inês e na constatação de Piazza e Pozenato (2010), evidencia-se a permanência de tradições como a preparação das comidas pelas cozinheiras mais experientes da comunidade, a manutenção das receitas herdadas, os modos de fazer, a origem dos ingredientes e os pratos identitários, que no caso são o Agnolini e o Tortei. Contudo, o que chama a atenção são as relações de reciprocidade que envolvem a programação da festa, mas que alcançam seu ápice na preparação dos alimentos pelas mulheres da comunidade. Neste contexto, Certeau et al. (2011: 20) relatam que:

A preparação de uma refeição oferece aquela rara felicidade de fazer pessoalmente alguma coisa, dar forma a algum fragmento real, conhecer as alegrias de uma miniaturização demiúrgica que garante o reconhecimento daquelas que a consumirão através de inocentes e prazerosas seduções.

Identificam-se na fala de Inês, ainda, questões que envolvem a origem, a qualidade dos alimentos, a forma de produção, a aprovação da fiscalização sanitária municipal e a percepção sobre risco alimentar. Neste caso, o exemplo está no ovo da colônia, ingrediente fundamental para a confecção das massas, prato emblemático na cozinha ítalo-brasileira de Antônio Prado. Este debate se insere na abordagem de Poulain (2013) sobre as dimensões sociais e culturais 
do sistema alimentar como um conjunto de estruturas tecnológicas e sociais que permeia todas as etapas do processo de produção e transformação até chegar a cozinha, permitindo o reconhecimento do alimento como comestível. Estas questões colocam em debate a identidade do alimento e da comunidade, evidenciando as dificuldades que envolvem a permanência do saber fazer local, a qualidade dos produtos e o risco alimentar.

Em relação à comida da Noite Italiana, evento turístico que recebe cerca de três mil pessoas por noite, e no qual se pretende reproduzir os costumes dos imigrantes italianos que chegaram à região há mais de 140 anos, a percepção de Júlia é:

\begin{abstract}
Comida inventada para festa... Tem gente que come copa, salame, queijo. Na minha casa não tem isto todo o dia, eu não uso copa, salame, toda hora. De pequena não tinha as conservas. Tinha, conforme a época, cebolinha no vinagre e pimentão, pepino - não consigo me ligar dele. Eu acho que eles estão fazendo uma forma de servir... Teve as mais diversas, foram mais de trinta e cinco. Foram diversas tentativas de comida, e agora uma comida que não faz mal para ninguém, uma comida que o italiano come, foi tirado a massa, tem frango, tem queijo, tem salada, tem chimia (Júlia, 2016).
\end{abstract}

No excerto de Júlia é possível refletir sobre cultura e alimentação através do conceito de Montanari (2013), quando diz que a cultura é o ponto de intersecção entre tradição e inovação. É tradição por ser formada pelos saberes, pelas técnicas e pelos valores que nos sãos transmitidos. É inovação porque os saberes, técnicas e valores modificam a posição dos sujeitos, tornando-os capazes de vivenciar novas realidades. A comida da festa Noite Italiana mantém pratos que remetem a identidade dos ítalo-brasileiros, tais como a Polenta, o salame, o Galeto, porém a escolha dos mesmos está relacionada, em maior medida, com a capacidade de prestação dos serviços de alimentação e entretenimento tanto para moradores locais como para turistas, nesta fusão surge uma comida híbrida e multicultural, marcada pelas mudanças tecnológicas, a urbanização e o modelo de produção local ligado à agricultura.

\title{
5. Conclusão
}

Ao tomar como ponto de reflexão o atual momento do município de Antônio Prado, em termos de comidas de festa, evidenciam-se as mudanças expressivas na matriz de alimentação dos migrantes italianos desde a sua chegada até o momento. Na primeira fase as adaptações e substituições foram em todos os aspectos da vida dos migrantes, tanto em relação ao uso da terra, o saber fazer, os modos de produção, os tipos de cultivos, os produtos e ingredientes, as relações sociais, entre outras. Deste modo, entende-se que o processo de hibridação cultural transformou a comida tida como italiana, em ítalo-brasileira, ainda marcada por ruralidades, num processo de adaptações, substituições e apropriações tanto pelos imigrantes como pelos migrantes. Neste sentido, a cultura é um processo de montagem multinacional, uma articulação flexível de partes, uma colagem de traços que qualquer cidadão de qualquer país, religião ou ideologia pode ler e utilizar (Canclini, 2008).

A segunda fase, que inicia em 1930 e tem seu término nos anos 1970, consolida os modos de vida do migrante, que apropriado das mudanças da primeira fase passa por um novo período de adaptação. A obtenção de luz elétrica, a industrialização, tanto alimentar como da agricultura, a mudança do rural para o urbano, a mídia televisiva, entre outros, são responsáveis por um novo estilo de vida e de alimentação. Novas mudanças ocorrem, nos horários das refeições, nos tipos e origem dos alimentos, que deixa de ser no âmbito rural e autossuficiente, para depender do supermercado. Importante também é o surgimento de uma 
comida emblemática tratada como 'italiana', que reproduz pratos de uso cotidiano para dias de festa, e incorpora novos alimentos ao uso cotidiano.

A terceira fase intensifica as trocas culturais e torna a cozinha ainda mais híbrida, vive as tensões sobre a qualidade dos alimentos, incorpora a industrialização alimentar da mesma forma que busca o retorno pelo alimento da roça e a comida da 'mãe', cria cardápios que mesclam Lasanha (comida nova) à Polenta e recriam uma comida identitária e patrimonial voltada ao turista, através das festas. Deste modo, mesmo que ocorra um processo de homogeneização dos modelos alimentares cotidianos, resultado da mundialização da economia alimentar, os produtos tradicionais continuam sendo elaborados. Os sistemas alimentares são dinâmicos e associam continuamente elementos de continuação e de mudança, conforme registra a literatura (Contreras \& Gracia, 2011; Garine, 1987).

Em relação à projeção turística que a alimentação ítalo-brasileira toma em Antônio Prado, através da Noite Italiana, percebe-se que a comida ítalo-brasileira é um demarcador de identidade local e, em consonância com o turismo gastronômico, apresenta a alimentação como símbolo do lugar e da cultura do destino, associada a agricultura e ao imaginário da policultura, da cultura e da infraestrutura, visando incentivo à produção agrícola local e competitividade na relação local-global e promovendo a atratividade turística para um nicho de mercado com perfil de consumo específico.

Ainda, compreende-se que a $35 .^{a}$ Noite Italiana representa o contexto histórico dos sujeitos de Antônio Prado, oportuniza uma experiência autêntica dos modos de vida locais em mudança, mas como produto de consumo turístico atende as demandas do público visitante e, neste sentido, as comidas fazem parte da trajetória da (i)migração italiana, mas são apresentadas e servidas para atender ao fluxo de visitantes e, a partir disto, é uma ressignificação importante das manifestações dos modos de vida locais e, como identitária, sujeita a mudanças e inovações, sendo que o turismo se coloca conforme aponta Bhabha (1998), como uma forma de produção de uma imagem de identidade, o que implica a transformação do sujeito em relação ao outro.

\section{Referências bibliográficas}

Alfonso, M. J. P. (2005). Museos y patrimonio alimentario: del sistema de producción al reclamo turístico: el encuentro del Turismo con el patrimonio cultural: concepciones teóricas y modelos de aplicación. In A. S. Talavera \& L. P. Canals (Eds.), Anales Congreso de Antropología (pp. 213-230). Sevilla: Fundación El Monte.

Amon, D. \& Menasche, R. (2008). Comida como narrativa de memória social. Sociedade e Cultura, 11 (1), 13-21. doi: 10.5216/sec.v11i1.4467

Bertella, G. (2011). Knowledge in food tourism: The case of Lofoten and Maremma Toscana. Current Issues in Tourism 14 (4), 355-371. doi: 10.1080/13683500.2010.489638

Bhabha, H. K. (1998). O local da cultura. (Trad. M. Ávila, E. L. L. Reis \& G. R. Gonçalves). Belo Horizonte: UFMG.

Canclini, N. G. (2008). Culturas híbridas: Estratégias para entrar e sair da modernidade. São Paulo: Editora da Universidade de São Paulo.

Certeau, M. de., Giard, L. \& Mayol, P. (2011). A invenção do cotidiano. Vol. 2: Morar, cozinhar. (Trad. E. F. Alves \& L. E. Orth). Petrópolis: Vozes.

Contreras, J. \& Gracia, A. M. (2011). Alimentação, sociedade e cultura. Rio de Janeiro: Fiocruz.

DaMatta, R. (1986). O que faz o Brasil, Brasil? Rio de Janeiro: Rocco.

Du Rand, G. E., Heath, E. \& Alberts, N. (2003). The role of local and regional food in destination marketing: A South African situation analysis. Journal of Travel \& Tourism Marketing, 14 (3-4), 97-112.

Du Rand, G. E. \& Heath, E. (2006). Towards a framework for food tourism as an element of destination marketing. Current Issues in Tourism, 9 (3), 206-234. 
Everett, S. (2008). Beyond the visual gaze? The pursuit of an embodied experience through food tourism. Tourist Studies, 8 (3), 337-358.

FEE - Fundação de Economia e Estatística (2016). Perfil socioeconômico de Antônio Prado (2016)

Garine, I. de. (1987). Alimentação, culturas e sociedades. Correio da Unesco, 15 (7), 4-7.

Gastal, S. (2003). Posmodernidad y gastronomía. In J. M. Gandara, R. Schlüter, C. P. Dieste, G. C. Lacanau \& J. A. Norrild (Eds.), Gastronomía y turismo: Una introducción (pp. 89-100). Buenos Aires: Centro de Investigaciones y Estudios Turísticos.

Gastal, S. (2006). Tiempos post-modernos: Posibilidades para el turismo. Revista Estudios y Perspectivas en Turismo 15(3), 270-282.

Giard, L. (2011). Artes de Nutrir. In Certeau, M. de., Giard, L. \& Mayol, P., A invenção do cotidiano. Vol. 2: Morar, cozinhar. (Trad. E. F. Alves \& L. E. Orth). Petrópolis: Vozes.

Hall, S. (2003). Da Diáspora: Identidades e Mediações Culturais. (Org. L. Sovik; Trad. A. La Guardia Resende et al.) Belo Horizonte: UFMG.

Herédia, V. B. M. \& Tronca, B. (2016). Patrimônio industrial e turismo: A vila operária de Galópolis, Caxias do Sul, RS. Rosa dos Ventos - Turismo e Hospitalidade, 8 (3), 343-357. doi: 10.18226/21789061.v8i3p343

Lorenzoni, J. (1975). Memórias de um imigrante italiano. Porto Alegre: Sulina.

Montanari, M. (2013). Comida como cultura. São Paulo: Senac.

Nummedal, M. \& Hall, C. M. (2006). Local food in tourism: An investigation of the New Zealand south island's bed and breakfast sector's use and perception of local food. Tourism Review International 9(4), 365-378. doi: 10.3727/154427206776330571

Peccini, M. R. \& Campillo, L. (2012). A invenção da galeteria: O galeto al primo canto e o patrimônio gastronômico de Caxias do Sul. Anais I Seminário sobre Alimentos e Manifestações Culturais Tradicionais. Universidade Federal de Sergipe, São Cristóvão, SE.

Piazza, C.M. \& Pozenato, J.C. (2005). Programa de Salvamento do Patrimônio Histórico e Cultural nas Áreas do Complexo Energético Rio das Antas. Caxias do Sul: ECIRS-UCS, CERAN.

Piazza, C.M. \& Pozenato, J.C. (2010). Projeto Inventário da Diversidade Cultural da Imigração Italiana: O Talian e a Culinária. Caxias do Sul, IPHAN, Instituto Vêneto, FIBRA-RS, ECIRS-UCS.

Poulain, J-P. (2013). Sociologias da alimentação: Os comedores e o espaço social alimentar. (Trad. R. P. C. Proença, C. S. Rial \& J. Conte). Florianópolis: UFSC.

Schlüter, R. G. (2003). Gastronomia e turismo. São Paulo: Aleph.

Sims, R. (2009). Food, place and authenticity: Local food and the sustainable tourism experience. Journal of Sustainable Tourism, 17(3), 321-336. doi:_10.1080/09669580802359293

ANA MARIA COSTA BEBER participa no Programa de Pós-Graduação em Turismo e Hospitalidade, Universidade de Caxias do Sul. Endereço institucional: Universidade de Caxias do Sul, Rua Francisco Getúlio Vargas, 1130, bloco 46, 4. ${ }^{\circ}$ andar, CEP 95070-560 - Caxias do Sul, RS, Brasil.

SUSANA GASTAL é Professora do Programa de Pós-Graduação em Turismo e Hospitalidade na Universidade de Caxias do Sul, Brasil. Lattes: http://lattes.cnpq.br/0363951380330385

Orcid: http://orcid.org/0000-0001-5706-9672; ResearcherID: G-4408-2012. Endereço institucional: Universidade de Caxias do Sul, Rua Francisco Getúlio Vargas, 1130, bloco 46, 4. ${ }^{\circ}$ andar, CEP 95070-560 Caxias do Sul, RS, Brasil.

Submetido em 15 setembro 2016

Aceite em 20 março 2017 